\title{
ESTIMATIVAS DE BIOMASSA E CARBONO EM FRAGMENTO DE FLORESTA ESTACIONAL SEMIDECIDUAL NO OESTE DO PARANÁ
}

\author{
BIOMASS AND CARBON ESTIMATES IN SEASONAL SEMIDECIDAL FOREST FRAGMENT IN \\ THE WEST OF PARANÁ
}

\author{
Qohélet José laniski Veres ${ }^{1}$, Luciano Farinha Watzlawick², Richeliel Albert Rodrigues Silva ${ }^{3}$ \\ 1, 2, 3 Universidade Estadual do Centro-Oeste, Irati, PR, Brasil-richelielufrn@gmail.com, \\ farinha@unicentro.br\& richeliel@yahoo.com.br
}

\begin{abstract}
RESUMO
As formações florestais são responsáveis por armazenar diferentes quantidades de carbono na biomassa, em função da intensificação do efeito-estufa e, consequentemente, do aquecimento global. Diante da importância dessa temática, foram testadas as seguintes hipóteses: o ajuste de modelos alométricos a partir das arvores individuais provindas da classificação dos Valores de Importância (VI) são eficientes? Neste sentido, o presente estudo teve por objetivo ajustar e estimar valores referentes à biomassa e ao carbono estocado total e por componentes em um fragmento de Floresta Estacional Semidecidual, no município de São José das Palmeiras, PR. Foram abatidas 32 árvores-amostra em 2008, para o ajuste das equações alométricas, as quais foram selecionadas por meio do ranqueamento do valor de importância (VI). Os coeficientes de determinação ajustado $\left(R^{2}\right.$ adj.) variaram de $0,11 \%$ a $0,90 \%$ e o erro padrão de $141,89 \%$ a $41,53 \%$, para biomassa dos componentes; $R^{2}$ adj. de $0,03 \%$ a 0,87 e erro padrão de $143,64 \%$ a $46,20 \%$, para carbono estocado nos componentes. Estimou-se em 56,25 t.ha-1 a biomassa total do componente arbóreo e 25,88 t.ha-1 $^{-1}$ de carbono total. Portanto, o método testado de ajustar modelos alométricos a partir das árvores individuais provindas da classificação dos valores de importância (VI) teve êxito. Os valores de biomassa total, carbono orgânico estocado e carbono efetivamente sequestrado são condizentes com o perfil da área do estudo.
\end{abstract}

PALAVRAS-CHAVE: Biomassa acima do solo, Crédito de Carbono, Equações alométricas, Mudanças climáticas.

\section{ABSTRACT}

The forest formations are responsible for storing different amounts of carbon in the biomass, as a result of the intensification of the greenhouse effect and consequently of global warming. In view of the importance of this theme, the following hypotheses were tested: are the adjustment of allometric models from the individual trees from the Importance Values (VI) classification efficient? In this sense, the present study aimed to adjust and estimate biomass and total stock and component carbon values in a fragment of the Semideciduous Seasonal Forest, in the municipality of São José das Palmeiras, PR. 32 sample trees were harvested in 2008 to adjust the allometric equations, which were selected by ranking the importance value (IV). The adjusted determination coefficients ( $\mathrm{R}^{2}$ adj.) ranged from $0.11 \%$ to $0.90 \%$ and the standard error from $141.89 \%$ to $41.53 \%$, for biomass of the components; $R^{2}$ adj. from $0.03 \%$ to 0.87 and standard error from $143.64 \%$ to $46.20 \%$, for carbon stored in the components. The total biomass of the tree component and 25.88 tha $^{-1}$ of total carbon were estimated at 56.25 t.ha-1 ${ }^{-1}$ Using the future distributions using the movement ratio method, the total stored carbon (aerial + roots) was estimated at $14.44 \mathrm{t}^{\text {.ha-1 }}{ }^{-1}$ over the 20 -year period. Therefore, the method tested to fit allometric models from the individual trees from the importance values rank classification was successful. The values of total biomass, stored organic carbon, and effectively sequestered carbon are consistent with the profile of the study area.

KEYWORDS: Above-ground biomass, Carbon credit, Allometric equations, Climatic changes. 


\section{INTRODUÇÃO}

Em estudo realizado pelo IPCC (2000) foram gerados vários cenários de mudanças climáticas para todos os continentes para o final do século XXI, com base nas taxas de emissões crescentes de poluentes na atmosfera, desde a década de 1980, prevendo um aumento na temperatura de $1,4{ }^{\circ} \mathrm{C}$ a $5,8{ }^{\circ} \mathrm{C}$. Essa mudança na temperatura desencadearia vários fenômenos e intensificaria os existentes como El Niño e La Niña, havendo grande possibilidade de alterar, prolongar e intensificar os regimes de chuvas e secas.

Neste contexto, os Gases de Efeito Estufa (GEE) são os maiores influenciadores para as alterações climáticas e o aquecimento global. Também se estima que as emissões de GEE oriundas da agricultura e associadas à alteração no uso da terra corresponderam a $30 \%$ das emissões antropogênicas globais em 2010 (SLADE et al., 2016).

Em 2009, pelo Acordo de Copenhague, foi reconhecida a importância da redução das emissões geradas pelo desmatamento e pela degradação das florestas (UNFCCC, 2009), gerando uma grande oportunidade aos países detentores dessas reservas florestais, que podem obter grande ganho para a sua biodiversidade, por meio da redução da perda de carbono.

Essa alternativa para reduzir a concentração de dióxido de carbono por meio de florestas naturais é uma grande oportunidade para o Brasil, país detentor de grandes biomas florestais, recuperar os distúrbios antrópicos, como a Floresta Estacional Semidecidual. No estado do Paraná, esta formação florestal se limita a pequenos fragmentos, e o REED pode ser uma alternativamente economicamente viável, em que os países que estão dispostos e possuem condições de reduzir as emissões por desmatamento deveriam ser recompensados financeiramente.

De acordo com Karousakis (2009), o REDD foi ampliado para incluir também a conservação, o manejo florestal sustentável e o aumento dos estoques de carbono. Diante disso, as mudanças climáticas tornaramse uma oportunidade a ser encarada pelo setor florestal (MELO et al., 2015).

Dúvidas surgem em relação à quantificação dos estoques de carbono nas diferentes formações florestais e quanto a outros diversos aspectos metodológicos, sendo estes os principais entraves científicos para se incluir integralmente a questão florestal em um mecanismo dentro da Convenção.

Diante da importância dessa temática, foram testadas as seguintes hipóteses no presente estudo: o ajuste de modelos alométricos a partir das arvores individuais provindas da classificação dos Valores de Importância (VI) são eficientes, com isso haverá alteração na capacidade atual e futura de fixação do carbono. Assim, objetivou-se ajustar modelos alométricos, para estimar a biomassa e o carbono do componente arbóreo de um fragmento de Floresta Estacional Semidecidual, em São José das Palmeiras, PR.

\section{MATERIAL E MÉTODOS}

Os dados utilizados no estudo são provenientes de uma unidade amostral permanente instalada em 2007, no município de São José das Palmeiras, PR, pertencente à formação Floresta Estacional Semidecidual. Foram obtidos os parâmetros absolutos e relativos da densidade, dominância e frequência nas parcelas, dando subsídios para determinar os valores de importância (VI). Foram iniciados os estudos de biomassa e carbono a partir destes dados, do ano de 2008.

Para determinação da biomassa arbórea acima do solo, foi empregado o método da árvore individual, havendo, no entanto, uma adaptação, onde foram selecionadas as espécies que obtiveram os maiores valores de importância (VI), devido a sua atribuição de representatividade para o restante da população.

Foram abatidas 31 árvores vivas e uma morta, as quais são pertencentes a 29 espécies diferentes, e para o ajuste dos modelos alométricos, foram utilizados apenas os dados dos indivíduos que possuíam os respectivos compartimentos. Com as árvores derrubadas, os componentes foram separados em fuste, casca, galhos vivos, galhos mortos, folhas e miscelânea (frutos, flores, sementes entre outros).

A etapa seguinte consistiu na pesagem das toras, com a utilização de uma balança de vara, neste processo foi incluída toda maravalha oriunda do traçamento, obtendo assim a biomassa verde do fuste com casca. Após a operação, foram coletados discos nas posições inferior, médio e superior da árvore, com uma espessura em torno de $2 \mathrm{~cm}$, que foram acondicionados em sacos de papel com a respectiva identificação.

A biomassa da casca foi determinada por meio da proporção entre casca e fuste. Para isso, as cascas foram separadas dos discos amostrados a 0,50 e $100 \%$ da altura total, pesados em balança eletrônica com precisão de 0,001 g. Obteve-se então a média dos valores de casca por quantidade de fuste do disco, e este valor médio foi extrapolado para o restante do fuste.

Para determinar a biomassa dos galhos, estes foram 
separados em mortos e vivos, e os galhos vivos ainda foram separados em galhos e folhas. Estes componentes foram pesados em balança de precisão de 0,1 g. Foram considerados como galhos os componentes acima do ponto de inversão morfológica.

Para cada componente foram coletadas amostras de aproximadamente $1000 \mathrm{~g}$, identificadas e armazenadas em sacos de papel, sendo que o material coletado dos galhos diferiu em diferentes diâmetros e as folhas foram retiradas da ponta, do meio e da base da copa, buscando uma fiel representatividade das condições reais.

As amostras coletadas de cada um dos componentes, após serem identificados e armazenados, foram levadas ao laboratório da UNICENTRO, Campus do CEDETEG, em Guarapuava, PR, onde se procedeu a secagem em estufas com circulação de ar forçada, iniciando a secagem a $60^{\circ} \mathrm{C}$ e finalizando a $70^{\circ} \mathrm{C}$, até a estabilização do peso.

Após a secagem, o material foi triturado em moinho tipo Wiley (peneira Mesch 20), para análise de biomassa e posterior análise do teor de carbono orgânico. As análises de carbono orgânico no tecido vegetal foram realizadas no laboratório da Universidade Federal de Santa Maria, Estado do Rio Grande do Sul, pelo método WALKLEYBLACK, com calor externo, proposto por Tedesco et al. (1995).

Neste trabalho foram testados 17 modelos para estimar biomassa estocada total e para os componentes (Tabela 1). Os modelos foram ajustados com o uso do software Microsoft Office Excel 2003.

A correção da discrepância logarítmica, presente nas estimativas das equações de modelos logarítmicos linearizados, foi feita multiplicando-se a quantidade do compartimento estimado pela expressão conhecida como índice de Meyer (IM): IM = e $\mathrm{e}^{0,5 * \mathrm{~s} 2 \mathrm{yx}}$, em que: $\mathrm{e}=$ base dos logaritmos neperianos e $S^{2} y x=$ quadrado do erro padrão da estimativa.

Para selecionar as melhores equações, foram analisados os seguintes critérios estatísticos de regressão: coeficiente de determinação ajustado ( $R^{2}$ aj.), erro padrão da estimativa expresso em porcentagem (Syx\%) e distribuição gráfica dos resíduos. Para estimar a quantidade de carbono estocado no componente arbóreo, realizou-se a multiplicação da biomassa pelo teor de carbono referente ao componente analisado.

Para estimar a serapilheira foram instaladas 50 parcelas de $625 \mathrm{~cm}^{2}(25 \times 25 \mathrm{~cm})$ cada, alocadas em todas as subunidades impares de $100 \mathrm{~m}^{2}$ da unidade amostral permanente, dispostas uma no canto inferior e outra no superior, de onde se procedeu a coleta e pesagem de todo o material em estágio de decomposição ali presente. Retirou-se uma amostra de cada parcela, com valor aproximado de um $\mathrm{kg}$, para posterior secagem e determinação do teor de carbono. Estes valores foram extrapolados para toda a unidade amostral e para o hectare.

Para estimar biomassa do sub-bosque, instalou-se 25 unidades amostrais de $u m \mathrm{~m}^{2}$, dispostas em todas as subunidades impares, onde foi realizada a coleta e pesagem de todo material vivo e retirada de amostras, as quais foram secas em laboratório, para determinação do peso seco e do teor de carbono, os quais foram extrapolados por unidade de área.

A estimativa da quantidade de dióxido de carbono $\left(\mathrm{CO}_{2}\right)$ armazenado na floresta foi realizada por meio dos valores totais de carbono estimados para todos os componentes descritos anteriormente, ou seja, carbono estocado no componente arbóreo, arbustivo e na serapilheira, e a soma destes foi multiplicada pelo fator de conversão obtido pela razão entre a massa atômica do dióxido de carbono (44) e a massa atômica do carbono (12), resultando no fator 3,6667 .

Tabela 1. Modelos utilizados para estimar biomassa e carbono estocado em um fragmento da Floresta Estacional Semidecidual, no município de São José das Palmeiras, PR.

\begin{tabular}{|c|c|}
\hline Número & Modelos \\
\hline 1 & $y=\beta_{0} \mathrm{~d}^{b}$ \\
\hline 2 & $\mathrm{y}=b_{0}+b_{1} d+b_{2} \mathrm{~d}^{2}$ \\
\hline 3 & $\mathrm{y}=b_{0}+b_{1} \mathrm{~d}+b_{2}\left(\mathrm{~d}^{2} \mathrm{~h}\right)$ \\
\hline 4 & $\mathrm{y}=b_{o}+b_{1} \mathrm{~d}+b_{2} \mathrm{~d}^{2}+b_{3}\left(\mathrm{~d}^{2} \mathrm{~h}\right)$ \\
\hline 5 & $\mathrm{y}=b_{0}+b_{1} \mathrm{~d}^{2}+\mathrm{b}_{2}\left(\mathrm{~d}^{2} \mathrm{~h}\right)$ \\
\hline 6 & $\mathrm{y}=b_{0}+b_{1} \mathrm{~d}+\mathrm{b}_{2} \mathrm{~h}$ \\
\hline 7 & $\mathrm{y}=b_{0} \mathrm{~d}^{b} \mathrm{~h}^{c}$ \\
\hline 8 & $\mathrm{y}=b_{0}+b_{1} \mathrm{~d}$ \\
\hline 9 & $y=b_{0}+b_{1} d^{2}$ \\
\hline 10 & $\mathrm{y}=b_{o}+b_{1} \mathrm{~d}^{3}$ \\
\hline 11 & $\mathrm{y}=b_{0}+b_{1} \mathrm{~d}^{2} \mathrm{~h}$ \\
\hline 12 & $\ln \mathrm{y}=b_{o}+b_{1} \ln \left(\mathrm{d}^{2} \mathrm{~h}\right)$ \\
\hline 13 & $\mathrm{y}=b_{0}+b_{1} \mathrm{~d}+b_{2} \mathrm{~d}^{2}+b_{3} \mathrm{~d}^{3}$ \\
\hline 14 & $\mathrm{y}=b_{0}+b_{1} \mathrm{~d}+b_{2} \mathrm{~d}^{2}+b_{3} \mathrm{~d}^{3}+b_{4} \mathrm{~d}^{4}$ \\
\hline 15 & $\mathrm{y}=b_{o}+b_{1} \mathrm{~d}+b_{2} \mathrm{~d}^{2}+b_{3} \mathrm{~d}^{3}+b_{4} \mathrm{~d}^{4}+b_{5} \mathrm{~d}^{5}$ \\
\hline 16 & $\ln \mathrm{y}=\mathrm{y}=b_{o}+b_{1} \ln \mathrm{h}$ \\
\hline 17 & $\mathrm{y}=b_{0}+b_{1} \mathrm{~d}^{2}+b_{2} \mathrm{~h}^{2}+b_{3}\left(\mathrm{~d}^{2} \mathrm{~h}\right)$ \\
\hline
\end{tabular}




\section{RESULTADOS E DISCUSSÃO}

\section{Conjunto de dados utilizados no ajuste das equações}

Na Tabela 2 estão listadas as espécies que foram selecionadas para os ajustes das equações e as suas medidas de DAP $(\mathrm{cm})$ e altura total $(\mathrm{m})$, bem como o valor de importância obtido para a espécie.

Observa-se que as 29 espécies presentes no fragmento que tiverem indivíduos amostrados para a determinação da biomassa e carbono correspondem a $74,8 \%$ do VI total da floresta, indicando que tais espécies representam bem a estrutura do remanescente, podendo, portanto, servir como base para a estimativa destes parâmetros para o restante da floresta.

\section{Teor de Carbono para as espécies e para os componentes}

O valor médio do teor de carbono foi de 431,68 g. $\mathrm{kg}^{-1}$, com valores médios do teor de carbono apresentaram uma variação de 401,32 a 457,71 g. $\mathrm{kg}^{-1}$ entre as espécies, e de 410,52 a 444,12 entre os componentes (Tabela 3). Pode-se constatar que utilizar o valor padrão de 0,500 g. $\mathrm{kg}^{-1}$ para estimar carbono estocado na biomassa arbórea, para Floresta Estacional Semidecidual ocorre superestima dos valores, proporcionando erros na quantificação.

A espécie Chorisia speciosa foi a que obteve menor teor médio de Carbono, com valor de 401,32 g. $\mathrm{kg}^{-1}$. Desta espécie, o componente galho morto foi o que apresentou o menor teor de carbono $\left(381,83 \mathrm{~g} . \mathrm{kg}^{-1}\right)$ sendo este o valor mais baixo observado entre os componentes. Por outro lado, Nectandra megapotamica foi a espécie que apresentou o maior teor médio de carbono, com 457,71 g. $\mathrm{kg}^{-1}$. As equações para obtenção biomassa e carbono dos galhos mortos foram as seguintes: PS $=-2,0051+$ $0,1431 d+0,0611 d^{2}-0,0047\left(d^{2} h\right)$ e $C=-0,5787+0,0436 d$ $+0,02067 d^{2}-0,00159\left(d^{2} h\right)$, respectivamente. Os galhos mortos foram os que apresentaram o maior valor para esta espécie, com 502,35 g. $\mathrm{kg}^{-1}$. Entretanto, as folhas de Annona rugulosa apresentaram o maior teor de carbono entre os componentes $\left(518,42 \mathrm{~g} \cdot \mathrm{kg}^{-1}\right)$.

Em estudos em um fragmento de Floresta Ombrófila Mista, Oliveira et al. (2016) verificaram que a Nectandra megapotamica é uma das espécies com maior quantidade de carbono, corroborando com o resultado encontrado no presente estudo. Em relação ao carbono médio, considerando todas as espécies arbóreas, o valor foi semelhante ao obtido por Ferez (2010) (460 g. kg ${ }^{-1}$ ).
De modo geral, o teor de carbono nos componentes seguiu esta tendência: madeira do fuste > folhagem $>$ galhos mortos > miscelância > galhos vivos > casca. Considerando os componentes, os resultados estão dentro do esperado, assemelhando-se com os verificados por Watzlawick et al. (2011), que constataram a seguinte tendência no teor de carbono: folhagem > galhos mortos $>$ madeira do fuste $>$ galho vivo $>$ casca. A única diferença foi na avaliação do componente miscelânia, que não foi avaliado no referido trabalho.

\section{Estimativas de biomassa e Carbono acima do solo}

Com base nos dados de biomassa e carbono das árvores, foram ajustadas equações para a estimativa da biomassa e carbono totais e para os componentes. As estatísticas de análise das equações para estimar a biomassa do componente arbóreo total apontam a seguinte equação: $P S=-4,8639+0,3981 . d+0,2625 d^{2}$, $\operatorname{com}\left(\operatorname{Syx}(\%)=50,98\right.$ e $R^{2}$ adj $\left.=0,70\right)$ e Ctot $=9,5139+$ $0,00268 \mathrm{~d}^{2} \mathrm{~h} \quad\left(\right.$ Syx $(\%)=46,27$ e $\mathrm{R}^{2}$ adj $\left.=0,73\right)$, respectivamente. Foi registrado 56,25 ton.ha- ${ }^{-1}$ de biomassa.

A alta variação encontrada nas florestas nativas, que possuem grande heterogeneidade de espécies, de tamanhos diferentes e densidade da madeira variável, sendo comum encontrar árvores tortas, com fuste pequeno e grande dimensão de copa, se reflete em alta variação na determinação da biomassa e carbono, como pode ser observado também nos gráficos de dispersão dos resíduos.

Silva et al. (2018) avaliando a biomassa e carbono no Parque Natural Municipal do Curió, Paracambi, RJ, observaram valores de 212,39 ton.ha-1 e 106,19 ton.ha-1, respectivamente. Valores superiores ao observado no presente estudo, provavelmente devido ao seu estágio sucessional e status de conservação.

Já em Floresta Estacional Semidecidual Montana madura em Minas Gerais, com pelos menos 100 anos sem intervenção antrópica, Ribeiro et al. (2009), estimaram em 166,67 t.ha-1 de biomassa aérea. Watzlawick (2003) realizou estudos de quantificação da biomassa e carbono em espécies arbóreas de um fragmento de Floresta Ombrófila Mista, em General Carneiro, PR, verificando que a biomassa média produzida pela floresta foi de 250,90 t.ha $^{-1}$. Os referidos valores são divergentes do que foi obtido no presente estudo. 
Tabela 2. Espécies selecionadas para os ajustes dos modelos alométricos.

\begin{tabular}{|c|c|c|c|c|}
\hline Nome Popular & Nome científico & CAP & HT & VI \\
\hline Angico vermelho & Parapiptadenia rigida (Benth.) Brenan & 45,30 & 12,22 & 2,43 \\
\hline Ariticum & Annona sp. & 28,40 & 8,52 & 1,24 \\
\hline Ariticum preto & Annona rugulosa (Schltdl.) H.Rainer & 25,30 & 3,92 & 0,62 \\
\hline Ariticum preto & Annona rugulosa (Schltdl.) H.Rainer & 17,00 & 6,24 & - \\
\hline Cabreúva & Myrocarpus frondosus Allemão & 23,50 & 8,89 & 5,36 \\
\hline Café de bugre & Cordia ecalyculata Vell. & 24,70 & 7,48 & 2,55 \\
\hline Caliandra & Calliandra foliolosa Benth. & 17,70 & 5,3 & 1,18 \\
\hline Canela & Nectandra megapotamica (Spreng.) Mez & 61,60 & 12,05 & 7,05 \\
\hline Catiguá miudo & Trichilia elegans A.Juss. & 19,60 & 5,98 & 0,15 \\
\hline Embauba & Cecropia pachystachya Trécul & 45,00 & 9,82 & 3,06 \\
\hline Farinha seca & Albizia of niopoides (Spruce ex Benth.) Burkart & 41,90 & 10,02 & 3,28 \\
\hline Figueira & Ficus sp. & 40,70 & 9,83 & 1,56 \\
\hline Guabijú & Myrcianthes pungens (O. Berg) D. Legrand & 35,40 & 8,86 & 0,65 \\
\hline Guaçatunga & Casearia decandra Jacq. & 22,40 & 7,47 & 0,47 \\
\hline Guaritá & Astronium graveolens Jacq. & 20,30 & 6,46 & 2,95 \\
\hline Guatambú & Chrysophyllum gonocarpum (Mart. \& Eichl.) Engl. & 29,90 & 8,77 & 2,38 \\
\hline Guateria & Guarea kunthiana A. Juss. & 31,10 & 7,23 & 3,71 \\
\hline Ipê roxo & Tabebuia impetiginosa (Mart. ex A. DC.) Standl. & 28,90 & 9,5 & 0,97 \\
\hline Leiteiro & Peschiera australis (Müll. Arg.) Miers & 31,00 & 11,13 & 0,15 \\
\hline Limão do mato & Gymnanthes concolor Spreng. & 20,90 & 7,11 & 0,75 \\
\hline Lixeira & Aloysia virgata (Ruiz \& Pav.) Pers. & 32,00 & 9,00 & 11,00 \\
\hline Louro & Cordia trichotoma (Vell.) Arráb. ex Steud. & 34,20 & 13,17 & 1,86 \\
\hline Paineira & Chorisia speciosa A.St.-Hil. & 103,50 & 13,32 & 4,58 \\
\hline Pau amargo & Picramnia parvifolia Engl. & 23,00 & 7,1 & 3,12 \\
\hline Pau marfim & Balfourodendron riedelianum (Engl.) Engl. & 29,90 & 12,29 & 4,26 \\
\hline Peroba & Aspidosperma parvifolium A. DC. & 33,50 & 9,8 & 0,74 \\
\hline Pessegueiro bravo & Prunus brasiliensis (Cham. \& Schlecht.) D. Dietrish & 50,00 & 12,28 & 0,73 \\
\hline Sapuva & Machaerium stipitatum (DC.) Vogel & 37,20 & 11,91 & 5,82 \\
\hline Sapuva & Machaerium stipitatum (DC.) Vogel & 45,00 & 11 & - \\
\hline Tapiá & Alchornea triplinervia (Spreng.) Müll. Arg. & 34,50 & 8,85 & 0,81 \\
\hline Uvaia & Eugenia pyriformis Camb. & 23,10 & 8,90 & 1,35 \\
\hline Morta & - & 34,50 & 6,47 & - \\
\hline Total & & & & 74,8 \\
\hline
\end{tabular}


Tabela 3. Teor de Carbono para os indivíduos amostrados e para os seus respectivos componentes.

\begin{tabular}{|c|c|c|c|c|c|c|c|c|}
\hline \multirow[b]{2}{*}{ Nome Popular } & \multirow[b]{2}{*}{ Nome Científico } & \multicolumn{7}{|c|}{ Teor de Carbono - g kg-1 $^{-1}$} \\
\hline & & Casca & Folhas & Fuste & $\begin{array}{l}\text { Galhos } \\
\text { Mortos }\end{array}$ & $\begin{array}{l}\text { Galhos } \\
\text { Vivos }\end{array}$ & Miscelânea & $\begin{array}{l}\text { Média/ } \\
\text { Espécie }\end{array}$ \\
\hline Angico Vermelho & Parapiptadenia rigida (Benth.) Brenan & 436,94 & 453,70 & 448,32 & 426,60 & 436,86 & 443,00 & 440,90 \\
\hline Ariticum & Annona sp. & 402,37 & 422,52 & 448,22 & 438,65 & 438,29 & & 430,01 \\
\hline Ariticum Preto & Annona rugulosa (Schltdl.) H.Rainer & 422,71 & 428,10 & 438,90 & 437,51 & 437,95 & & 433,03 \\
\hline Ariticum Preto. & Annona rugulosa (Schltdl.) H.Rainer & 417,60 & 518,42 & 441,69 & 445,97 & 445,18 & & 453,77 \\
\hline Cabreúva & Myrocarpus frondosus Allemão & 426,17 & 416,87 & 428,65 & & 431,93 & & 425,91 \\
\hline Café de Bugre & Cordia ecalyculata Vell. & 405,40 & 428,20 & 438,23 & 433,89 & 433,76 & & 427,90 \\
\hline Caliandra & Calliandra foliolosa Benth. & 405,84 & 420,45 & 444,82 & & 432,81 & 437,61 & 428,30 \\
\hline Canela & Nectandra megapotamica (Spreng.) Mez & 396,48 & 482,66 & 455,22 & 502,35 & 451,82 & & 457,71 \\
\hline Catiguá Miúdo & Trichilia elegans A.Juss. & 415,95 & 462,56 & 447,94 & & 443,98 & & 442,61 \\
\hline Embaúba & Cecropia pachystachya Trécul & 399,31 & 395,11 & 451,63 & 431,49 & 433,24 & & 422,16 \\
\hline Farinha Seca & Albizia cf niopoides (Spruce ex Benth.) Burkart & 414,17 & 478,46 & 441,18 & & 434,11 & & 441,98 \\
\hline Figueira & Ficus sp. & 400,18 & 428,03 & 435,77 & & 411,79 & & 418,94 \\
\hline Guabijú & Myrcianthes pungens (O. Berg) D. Legrand & 407,26 & 408,89 & 451,42 & & 423,68 & & 422,81 \\
\hline Guaçatunga & Casearia decandra Jacq. & 389,27 & 473,44 & 436,87 & 423,63 & 426,50 & & 429,94 \\
\hline Guarita & Astronium graveolens Jacq. & 409,68 & 457,21 & 429,23 & 416,18 & 428,57 & & 428,17 \\
\hline Guatambu & Chrysophyllum gonocarpum (Mart. \& Eichl.) Engl. & 398,18 & 462,15 & 443,31 & 424,61 & 434,66 & & 432,58 \\
\hline Guateria & Guarea kunthiana A. Juss. & 405,16 & 385,39 & 441,78 & 427,25 & 409,78 & & 413,87 \\
\hline Ipê Roxo & Tabebuia impetiginosa (Mart. ex A. DC.) Standl. & 408,94 & 425,51 & 449,35 & & 446,38 & & 432,55 \\
\hline Leiteiro & Peschiera australis (Müll. Arg.) Miers & 400,20 & 439,79 & 462,96 & & 429,41 & & 433,09 \\
\hline Limão do Mato & Gymnanthes concolor Spreng. & 409,27 & 413,00 & 435,26 & 427,71 & 431,04 & & 423,26 \\
\hline Lixeira & Aloysia virgata (Ruiz \& Pav.) Pers. & 411,23 & & 443,97 & 440,42 & 441,23 & & 434,21 \\
\hline Louro & Cordia trichotoma (Vell.) Arráb. ex Steud. & 414,23 & 414,73 & 453,03 & 432,79 & 429,36 & 448,41 & 432,09 \\
\hline Morta & Morta & 423,40 & & 439,08 & 438,20 & & & 433,56 \\
\hline Paineira & Chorisia speciosa A.St.-Hil. & 388,26 & 420,95 & 413,59 & 381,83 & & 401,96 & 401,32 \\
\hline Pau Amargo & Picramnia parvifolia Engl. & 402,58 & 418,04 & 444,89 & 430,55 & 437,70 & & 426,75 \\
\hline Pau Marfim & Balfourodendron riedelianum (Engl.) Engl. & 391,48 & 417,83 & 441,35 & 433,55 & 413,14 & & 419,47 \\
\hline Peroba & Aspidosperma parvifolium A. DC. & 409,88 & 456,86 & 458,26 & 433,10 & 423,93 & & 436,41 \\
\hline Pessegueiro Bravo & Prunus brasiliensis (Cham. \& Schlecht.) D. Dietrish & 456,44 & 467,94 & 448,82 & 451,09 & 447,91 & & 454,44 \\
\hline Sapuva & Machaerium stipitatum (DC.) Vogel & 411,55 & 433,92 & 446,42 & 435,64 & 432,16 & & 431,94 \\
\hline Sapuva. & Machaerium stipitatum (DC.) Vogel & 418,89 & 426,25 & 463,49 & 433,51 & 427,66 & & 433,96 \\
\hline Tapiá & Alchornea triplinervia (Spreng.) Müll. Arg. & 435,26 & 465,58 & 439,13 & 439,90 & 436,01 & & 443,18 \\
\hline Uvaia & Eugenia pyriformis Camb. & 402,41 & 411,08 & 449,07 & 441,25 & 430,25 & & 426,81 \\
\hline Média & & 410,52 & 437,79 & 444,12 & 434,49 & 432,70 & 432,74 & 431,68 \\
\hline
\end{tabular}


Diante disso, pode-se afirmar que a biomassa acumulada em diferentes tipologias florestais é variável, bastante influenciada pelo estágio de sucessão da vegetação. Dessa forma, formações florestais em estágios mais avançados de sucessão, com a presença de indivíduos de grande porte, tendem a acumular quantidade maior de biomassa, enquanto formações em estágios iniciais apresentam um menor acúmulo, como detectado no presente estudo.

Como o teor médio de carbono foi de $431,68 \mathrm{~g} \cdot \mathrm{kg}^{-1}$ para o total, estimou-se em 24,28 ton.ha ${ }^{-1}$ de carbono orgânico estocado na parte aérea da vegetação.

Boina (2008) avaliando os estoques de carbono em FES em estágio inicial de sucessão constatou que os valores acumulados variaram de 36,70 t.ha $^{-1}$ a 44,44 t.ha1. Martins (2011) estimou valores semelhantes em um fragmento da Floresta Ombrófila Mista em estágios iniciais de sucessão, com 26,36 t.ha-1 de carbono estocado.

Embora a quantidade de carbono estocado não seja tão grande quanto em florestas avançadas, em formações em estágio inicial os processos dinâmicos são mais acentuados, como crescimento acelerado de espécies pioneiras, taxas elevadas de mortalidade e recrutamento, que podem propiciar uma maior capacidade de acúmulo, constituindo-se, portanto, em importantes sumidouros de $\mathrm{CO}_{2}$.

\section{Estimativas de biomassa e Carbono estocado nos galhos vivos}

As equações selecionadas para os cálculos da biomassa e Carbono foram as seguintes: PS $=-0,589+$ $0,0979 d^{2}-0,004\left(d^{2} h\right)\left(R^{2}\right.$ adj $=0,36$ e Syx $\left.(\%)=83,05\right)$ e $C$ $=-0,81001+0,668 \mathrm{~d}-0,3784 \mathrm{~h}\left(\mathrm{R}^{2}\right.$ adj $=0,38$ e Syx $(\%)=$ $84,34)$. A biomassa obtida foi de 10,1 t.ha $^{-1}$. Watzlawick (2003) quantificando a biomassa em Floresta Ombrófila Mista, constatou que os galhos vivos representam 93,42 t.ha-1 da biomassa seca, valor consideravelmente superior ao observado no presente estudo.

Observa-se que o presente estudo apresentou os menores valores para a biomassa dos galhos vivos que o referido trabalho. Tal fato pode ser atribuído às características morfológicas das espécies presentes na área de estudo, ou ainda, à presença majoritária de indivíduos de pequeno porte, cujos galhos de pequenas dimensões e, consequentemente, menores pesos.

Utilizando-se o teor de carbono médio para os galhos vivos de 432,7g. $\mathrm{kg}^{-1}$, estimou-se em 4,37 ton.ha-1 de carbono orgânico estocado nos galhos vivos da vegetação.
Comparativamente, Watzlawick (2003) avaliando os teores de carbono na Floresta Ombrófila Mista, concluiu que, em média, os valores são de 35,91 t.ha-1. Entretanto, conforme dados do autor, em algumas parcelas os teores foram semelhantes ao observado no presente estudo, como 4,60 t.ha-1.

\section{Estimativas de biomassa e Carbono da folhagem}

Das 17 equações ajustadas para a estimativa da biomassa da folhagem, nenhuma foi satisfatória para a este parâmetro. Todas as equações apresentaram um baixo $R^{2}$ adj, variando de 0,00 a 0,22 e alto $S_{y x} \%$, variando de $132 \%$ a $152 \%$. Tais resultados são decorrentes da baixa correlação entre as variáveis dentrométricas, como diâmetro e altura das árvores com a biomassa das folhas.

Martins (2011), modelando a biomassa da folhagem em Floresta Ombrófila Mista, também obteve resultados insatisfatórios em relação às estatísticas de precisão para a estimativa deste parâmetro, com $\mathrm{R}^{2}$ adj. variando de 0,393 a 0,391 e alto Syx\%, variando de 138,06\% a $164,53 \%$. Sendo assim, optou-se for não efetuar a estimativa destes parâmetros tendo em vista a incapacidade das equações testadas em representar com fidedignidade os valores reais da floresta.

\section{Estimativas de biomassa e Carbono estocados na madeira do fuste}

Os valores das estatísticas dos modelos ajustados indicaram valores aceitáveis para o $R^{2}$ adj. As equações de biomassa e Carbono foram as seguintes: $P S=-1,3007+$ $0,0169 d^{2} h\left(R^{2}\right.$ adj. $=0,77$ e Syx $=54,24 \%$ ) e $C=-13,1136+$ $4,2475 d-0,48015 d^{2}+0,0309 d^{3}-0,00058 d^{4}\left(R^{2}\right.$ adj. $=0,64$ e Syx $=66,17 \%)$, respectivamente.

A biomassa estimada para o fuste resultou em 42,11 t.ha ${ }^{-1}$. Valor semelhante foi encontrado por Martins (2011), que estimou a biomassa do fuste em 41,04 ton.ha1 . Por outro lado Watzlawick (2003) observou na Floresta Ombrófila Mista, a biomassa da madeira do fuste, de 86,29 t.ha $^{-1}$, valor consideravelmente superior ao observado no presente estudo. Entretanto, o autor observou que unidades com vegetação em estágio inicial de sucessão apresentaram valores de até 25,55 t.ha-1, atingindo até 271,47 t.ha $^{-1}$ em áreas com floresta mais maduras.

O teor médio de carbono para a casca foi de 410,52 g.kg-1 ${ }^{-1}$ obtendo 1,92 t.ha-1 ${ }^{-1}$ de carbono orgânico estocado da casca do fuste da vegetação, sendo que Martins (2011) estimou valor de 4,29 ton.ha-1 ${ }^{-1}$ para Floresta Ombrófila 
Mista. Watzlawick (2003), na mesma tipologia florestal, obteve média para o teor de carbono de 8,12 t.ha-1, com valores variando entre 0,44 a 63,45 t.ha-1.

\section{Estimativas de biomassa e Carbono orgânico na serapilheira}

Com base nas amostras de serapilheira coletada, estimou-se a biomassa média para o remanescente em 31 t.ha-1 ${ }^{-1}$ Santos (2011) avaliando a biomassa da serapilheira em Floresta Estacional Semidecidual obteve valores de 6,6 t.ha-1 a 14,0 t.ha-1. Martins (2011) também estudando a Floresta Ombrófila Mista obteve valor de 18,69 t.ha-1 para a biomassa da serapilheira.

Observando os trabalhos citados, os valores estimados para a biomassa da serapilheira do presente estudo foram consideravelmente superiores. Este fato pode ser atribuído à intensa deposição foliar por parte das árvores, visto se tratar de uma floresta semidecidual, onde 20 a $50 \%$ dos indivíduos tendem a perder suas folhas no inverno.

Em relação ao carbono estocado na serapilheira este foi estimado em 12,1 t.ha-1. Martins (2011) estimando o carbono na serapilheira em um remanescente de Floresta

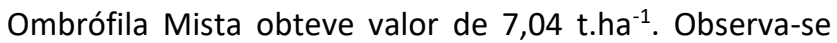
que, comparativamente, há menor acúmulo de carbono na serapilheira do que no presente estudo, fato atribuído às mesmas condições da biomassa deste componente.

\section{Estimativa de biomassa e Carbono da casca do fuste}

Foram selecionadas as seguintes equações para a obtenção de biomassa e carbono: PS $=-3,7956+0,8711 d$ $-0,0337 d^{2}+0,00094 d^{3}$ ( $R^{2}$ adj. $=0,90$ e Syx $=41,53 \%$ ) e $C$ $=-0,4873+0,0891 d+0,0056 d^{2}\left(R^{2}\right.$ adj. $=0,87$ e Syx $=$ $46,20 \%)$, respectivamente.

Empregando a equação selecionada, estimou-se a biomassa da casca para o fragmento, resultando em 4,67 ton.ha ${ }^{-1}$. Martins (2011) estimou a biomassa da casca em remanescente de Floresta Ombrófila Mista, obtendo valor de 9,68 t.ha-1. Watzlawick (2003) observou valor médio de 21,21 t.ha-1 para a biomassa da casca do fuste em Floresta Ombrófila Mista, com valores variando de 1,17 a 155,78 t.ha- ${ }^{-1}$, conforme estágio sucessional das unidades amostrais.

O baixo valor observado para a biomassa do componente casca no presente estudo pode ser atribuído ao pequeno porte dos indivíduos amostrados, que não apresentam casca espessa e abundante. Conforme observado, a biomassa da casca tende a aumentar à medida que se analisa remanescentes em estágios mais avançados, onde a presença de indivíduos de grande porte, com cascas mais espessas e abundantes, é maior.

\section{Estimativas de Biomassa e Carbono para o sub-bosque}

Com base nas amostras coletadas da vegetação do sub-bosque estimou-se a biomassa do remanescente florestal em 3,54 t.ha-1. Valor superior foi obtido por Martins (2011) na FOM, que estimou a biomassa nesse componente em 4,92 t.ha ${ }^{-1}$. Watzlawick (2003) obteve médias bem superiores, com valor igual a 21,85 t.ha-1, variando de 2,30 t.ha ${ }^{-1}$ até 80,83 t.ha ${ }^{-1}$, conforme estágio sucessional da floresta. Em relação ao carbono estocado no sub-bosque da floresta, a estimativa obtida no presente estudo foi de 1,50 t.ha-1.

Fatores como pouca regeneração natural e/ou vegetação herbácea na área de estudo interferiram na quantidade de biomassa e carbono estocados nesse componente, o que se atribui esta característica aos aspectos da vegetação, como densidade de indivíduos e características das espécies avaliadas.

\section{CONCLUSÕES}

O ajuste dos modelos tem maiores êxitos para os componentes da biomassa total, fuste, casca e galhos mortos em relação aos componentes folhas e galhos vivos.

O estágio médio/inicial da vegetação da área de estudo possibilita um menor acúmulo de biomassa e carbono na maioria dos componentes, quando comparado com outras formações em estágios mais avançados de sucessão.

A conservação do fragmento analisado permite um crescente acúmulo de biomassa e carbono, conforme as projeções realizadas, podendo constituir-se em uma alternativa de renda aos proprietários caso implantação de projetos de florestas geradoras de créditos de carbono sejam implantados.

\section{AGRADECIMENTOS}

O presente trabalho foi realizado com apoio da Coordenação de Aperfeiçoamento de Pessoal de Nível Superior - Brasil (CAPES) - Código de Financiamento 001.

\section{REFERÊNCIAS}

BOINA, A. Quantificação de estoques de biomassa e de carbono em floresta estacional decidual, Vale do Rio Doce, Minas 
Gerais. 2008. 98p. (Dissertação de mestrado).

CALDEIRA, M.V.W. et al. Quantificação da serapilheira e nutrientes - Floresta Ombrófila Mista Montana - Paraná. Revista Acadêmica, v.5, n.2, p.101-116, 2007.

DICK, G. et al. Produção de serapilheira em fragmento de Floresta Estacional Subtropical na região norte do Rio Grande do Sul. Ecologia e Nutrição Florestal, v.3, n.1, p.1-8, 2015.

FEREZ, A.P.C. Efeito de práticas silviculturais sobre as taxas iniciais de sequestro de carbono em plantios de restauração da Mata Atlântica. 2010. 106p. (Dissertação de mestrado).

IPCC. Emissions Scenarios - IPCC Special Report. IPCC Secretariat, c/o WMO, Geneva, Switzerland. 2000.

KAROUSAKIS, K. Promoting Biodiversity Co-Benefits in REDD. France: OECD. Publishing, 2009. OECD Environment Working Papers no 11. Disponível em: < http://www.cbd.int/doc/meetings/for/ewredd01/other/ewredd -01- oth-oecd-en.pdf>. Acesso em: 12/06/2019.

MARTINS, P.J. Biomassa vegetal, estoque de Carbono e dinâmica em um fragmento de Floresta Ombrófila Mista Montana. 2011. 73p. (Dissertação de mestrado).

MELO, L.C. et al. Cenários climáticos futuros para o Paraná: oportunidades para o setor florestal. Revista Brasileira de Climatologia, v.16, p.120-131, 2015.

OLIVEIRA, M. et al. Biomassa e estoques de Carbono em diferentes sistemas florestais no Sul do Brasil. Perspectiva, v.40, n.149, p.1-13, 2016.

RIBEIRO, S.C. et al. Quantificação de biomassa e estimativa de estoque de Carbono em uma Floresta madura no município de Viçosa, Minas Gerais. Revista Árvore, v.33, n.5, p.917-926, 2009.

SILVA, L.C. et al. Estoques de biomassa e Carbono em unidade de conservação no Bioma Mata Atlântica. Biofix Scientific Journal, v.3, n.2, p.243-251, 2018.

SLADE, E.M. et al. The role of dung beetles in reducing greenhouse gas emissions from cattle farming. Scientific Reports, v.6, p.1-8, 2016.

TEDESCO, M.J. et al. Análises de solo, plantas e outros materiais. Porto Alegre: Departamento de solos, UFRGS. 1995. 174p. (Boletim Técnico n. 5).

WATZLAWICK, L.F. Estimativa de biomassa e carbono em Floresta Ombrófila Mista e plantações florestais a partir de dados de imagens do satélite Ikonos II. 2003. 120p. (Tese de doutorado).

WATZLAWICK, L.F. et al. Variação nos teores de Carbono orgânico em espécies arbóreas da Floresta Ombrófila Mista. Floresta e Ambiente, v.18, n.3, p.248-258, 2011.

Recebido em 12-04-2019 Aceito em 08-07-2019 